\title{
Advantages and limitations of Virtual Classroom in Telugu Language Teaching
}

\author{
Dr. K. Mallareddy, \\ Lecturer in Telugu, SRR Government Degree \& P.G. College, Karimnagar, Andhra Pradesh, INDIA
}

\begin{abstract}
Pitroda, Teaching remains confined to blackboard, chalk, exams, marks and the like. The IT revolution has arrived and the internet, today, enables loads of packets of information to be accessed and explored. So, herein lies the need for generational changes. ICT can provide opportunities to enabling solutions for improving various existing approaches to content development and improve the quality of education, communicative skills must be incorporated in the present modern language curriculum and content development to protect the endangered Indian languages by updating the language technology. This paper analyses the challenges to present day curricular trends of Telugu language teaching and scope for the use of virtual classroom, which is the second largest spoken language in India listed in UNESCO atlas of endangered languages.

Key words: Language curriculum, Virtual Classroom, Virtual Education, Online pedagogy
\end{abstract}

\section{Introduction}

Education is the manifestation of the perfection already in man Swami Vivekananda. Manifestation of education in $21^{\text {st }}$ century is possible with the use of ICT (Information and Communication Technology) and use of multimedia which accelerated the education sector. The curriculum and content should be developed on the basis of present day needs of society. ICT can provide opportunities for improving various existing approaches to content development and improve the quality of education. It also improves the quality and efficiency of teaching learning process. Effective language teaching is depending on effective teaching learning communication. "One of the most neglected aspects of teacher training is thorough preparation in the diverse communication skills that are needed by good teacher in today's schools (Morgan, 1989). So these communication skills must be incorporated in the present modern language curriculum and content development.

As the age of computer-assisted and adaptive language learning become real concerns of the modern language teacher, it has become necessary to investigate the ways in which the computer can enhance existing teaching methods to improve the overall quality of language instruction. Many researchers have attempted to add their own electronic components to their favourite exercises [1]

Telugu is the second largest spoken language in India and $10^{\text {th }}$ largest language among 16 major languages of the world. But modern language concepts and language teaching approaches have not been inserted in Telugu Language curriculum, same concepts of content and subject topics were taught since last 5 decades. A new paradigm is developing in Indian education system with the influence of computer and internet. Now there is a necessity of shifting of chalk-black board teaching to mouse-monitor teaching to make teaching more effective and efficient. The gadget which the child uses for entertainment at younger age can be effectively used in helping to learn at secondary level of schooling and most effectively used in higher education. All these tremendous changes have been neglected in Telugu Language Teaching (TLT) in higher education so that the students are running far away from learning in their Mother Tongue Telugu. Today Telugu Language classrooms moving towards from full of students to nil of students. By the way Telugu Language is listed in the UNESCO atlas of endangered languages. There is an urgent need to incorporate modern language technology in Telugu Language curriculum and provide opportunities for e-content development and use of ICT in TLT.

\section{Virtual Classroom (VCR)}

Virtual means a simulation of the real thing, Virtual Classroom is a simulated classroom via internet. It allows the learners to attend a class from anywhere in the world. Virtual Education is a learning environment where the teacher and the students are separated by time and space or both. They communicate via Multimedia, Internet and Videoconferencing. Virtual Education in our country(India) is "provision of ubiquitous access to quality-oriented, low-cost, personalised learning to every citizen, irrespective of the age and type of education (Dr. Mrs. Laxmi priya).

Virtual Education is make possible only by the e-content development and use of ICT. In a virtual classroom students will be present with his teacher and fellow learners in the classroom, they will not present 
physically but connected to the classroom via internet, everyone will be able to share experiences with other participants virtually. VCR allows a single learner to access the information wherever and whenever required without bounded by group.

Language teachers need to be effective communicators with a thorough knowledge of various aspects of communication strategies in their dealings with their learners, knowing the fact that interpersonal communication skills form almost half of language teaching. Considering this fact, CLT has been appreciated by many applied linguists and language educators as an effective language teaching [2]

ICT improves the quality in higher education and access to remote areas, It promises a practical and realistic approach to curriculum development and makes the teaching learning process easy and effective. It is also most useful for slow learners and dropouts by making special Bridge Courses for them. ICT gives latest information and references in the subject by instant reforms. By the e-content development and use of ICT in TLT in VCR can overcome the unavailability of teaching resources in various parts of Telugu Habitats on the globe.

\section{Advantages of Virtual Classroom in Telugu Language Teaching}

In developing country like India, e-learning concept is an emerging opportunity to meet the educational desires of the millions of youth with universal quality educational materials. Presently the wed content is no longer with text matter but is stacked with audio visual media. Media software can be effectively used to produce e-learning course wares across all digital platforms-internet, mobile phones [3]

Following are some of the advantages of VCR teaching in Telugu Language over traditional classroom model.

\subsection{Removing the barriers of Time and Space}

Approximately 100 millions of Telugu speaking people living throughout the world among them about $50 \%$ are literates remaining 50\% are away from Telugu alphabets. A VCR can remove the barriers and allow the people to learn from anywhere at any time, providing they have computer and internet. Most of the students are very poor that they are earning at the age of learning, they can easily access to VCR during the leisure.

\subsection{Overcome the unavailability of Teachers}

A Large number of Telugu teaching posts are vacant today, especially in universities they are engaged by contract faculty. Effective teaching lesions by senior experts can be used in various classrooms at the same time. They are also very useful in distance mode of teaching.

\subsection{Sessions can be recorded}

Sufficient teaching material is not available in Telugu Language as well as in other subjects which are taught in Telugu Medium. If the learner miss the sessions of teaching there is no further opportunity to get it in the traditional classes which can be overcome by recorded sessions. Recorded sessions can be reviewed as many times as possible for slow learners and dropouts.

\subsection{Quicker to Organise}

Classrooms can be organised more quickly than traditional classes, they can be arranged anywhere and sessions are easier to schedule or reschedule, learners need not travel to the venue which saves the time and money. It is very useful for divergent Telugu people especially living in rural and remote areas.

Beyond the above all advantages VCR can develop the online pedagogy, efficient delivery and desired outcome. Learning is breaking out of the narrow boxes that it was trapped in during the $20^{\text {th }}$ century; teachers professionalism, reflection and ingenuity are leading to places that genuinely excite this new generation of connected young students-and their teachers too(Stephen heppell, 2007).

\section{Limitations of Virtual Classroom in Telugu Language Teaching}

Beyond all the above advantages following are some of the limitations of VCR teaching in Telugu Language over traditional classroom model.

\subsection{Lack of adequate Tools and Technology}

Online pedagogy is not developed up to the mark, computer software and new fonts have not developed in Telugu. Telugu Language Teachers are not aware of ICT and computer technology, they are afraid of following the recent trends in education system.

Virtual Reality (VR) environments have significant potential as a tool in mental health research, but are limited by technical factors and by mental health research factors. Technical difficulties include cost and complexity of virtual environment creation. Mental health research difficulties include current inadequacy of standards to specify needed details for virtual environment design [4] 


\subsection{Lack of Interaction with Learners}

There is no live interaction of learner with the teacher as well as co-learners, the effective teaching methodology that is Interaction and Question-Answer method is not possible to follow in VCR. The doubts of the learners remain unanswered, lapses the monitoring of the students. One of the basic principles of education is all-round development of the child which is not possible in this method due to lack of proper guidance and motivation.

\subsection{No Student Feedback}

The teacher is always to change his teaching methods and processes of teaching according to the needs and standards of the students which can be indicated by their feedback. But it is not possible in VCR and leads to monotony in teaching and learning process.

\subsection{Technical Limitations}

India is still a developing country, the computer technology and internet facilities are not available everywhere in the country Particularly in Telugu Language which are essential for VCR.

\section{Conclusion}

Learn as many languages as possible but don't neglect Mother Tongue. There is an urgent need to update all the Indian languages with modern language technology emerging throughout the world to protect the endangered Indian languages which are about to disappear in which Telugu Language is one among them. Instead of learning through the medium of already developed languages, need to concentrate on developing the Mother Tongues for medium of instruction to protect the cultural and traditional essence of each and every human being.

\section{References}

[1] Christopher M. Colburn dude [at] bert.eds.udel.edu Online Strategic Interaction: ESL Role-Playing via Internet Relay Chat Department of Linguistics, University of Delaware http://bert.eds.udel.edu/ dude/

[2] Shafeeq. C.P. Knowdge of pedagogy and ICT for effective communication in language teaching LANGUAGE IN INDIA Vol 13 : 1 Jan 2013 (177).

[3] P.Lalitha and A.Swanalatha, Digital content development for Indian higher education: progress, challenges, approaches and best practises, International convention on virtual education: issues, challenges and prospects 24-25 feb 2012 CCE-UGC New $\operatorname{Delhi}(22)$

[4] Giuseppe Riva, Brenda K. Wiederhold, Enrico Molinari (Eds.) Virtual Environments in Clinical Psychology and Neuroscience 1998 (C) Ios Press: Amsterdam, Netherlands.

[5] Short, D. (1991). Integrating Language and Content Instruction: Strategies and Techniques. NCBE Program Information Guide Series, 7 (Fall) [Online]. http://www.ncbe.gwu.edu/ncbepubs/pigs/pig7.html [Accessed June 7, 1997].

\section{Authors' Biography}

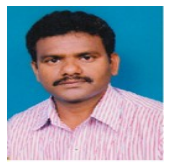

DR. K. MALLAREDDY received M.A (TELUGU) from Osmania University and honoured with Gold Medal for securing highest marks in the University Examinations from Osmania University, Hyderabad, India. Received M.Phil \& Ph.D from the same University. Received Teacher Training Certificate and Appointed as Teacher in 1996. Appointed as Lecture in Telugu through Andhra Pradesh Public Service Commission (APPSC) in 2002. Now working as Lecturer (Asst. Professor) in Telugu at SRR Government Degree \& P.G. College, Karimnagar, AP, India Asst. Published No. of articles in various ISSN \& ISBN refereed journals and Regional Daily News Papers, Presented technical paper in International conferences held at Kuala Lumpur, Malaysia, IASE, Pune and University of Madrass. Attended National \& International Seminars, actively participated in State level and National level Work Shops held Coimbatore, Tamilnadu. Started a Website www.ictltr.org on the name of International Centre for Telugu Language Teaching and Research. 